\title{
Daya Dukung Lingkungan dan Analisis Kesesuaian pada Wisata Hiu Paus (Rhincodon typus) di Taman Nasional Teluk Cenderawasih, Kabupaten Nabire
}

\author{
Carrying Capacity Enviroment and Suitable Analyse for Whale Shark Tourism \\ (Rhicodon typus) in Natinal Park Teluk Cenderawasih, Nabire Regency \\ Donny Juliandri Prihadi ${ }^{2}$, Aris Nuryana ${ }^{1}$, Walim Lili ${ }^{2}$, Yudi Nurul Ihsan ${ }^{2}$ \\ dan Evi Nurul Ihsan ${ }^{3}$ \\ ${ }^{1}$ Mahasiswa Program Studi Ilmu Kelautan, FPIK Universitas Padjadjaran, Jatinangor, Indonesia \\ ${ }^{2}$ Staff Pengajar Fakultas Perikanan dan Ilmu Kelautan Universitas Padjadjaran, Jatinangor, Indonesia \\ ${ }^{3}$ Staff Peneliti WWF Papua \\ *Email :donny.juliandri.prihadi@unpad.ac.id
}

\begin{abstract}
Abstrak
Penelitian ini dilakukan di Perairan Kwatisore, Taman Nasional Teluk Cenderawasih, Kabupaten Nabire untuk mengetahui kesesuaian kondisi lingkungan perairan dan daya dukung kawasan dalam mendukung pengembangan wisata hiu paus. Metode yang digunakan adalah cross section, dimana data bersumber dari data primer dan data sekunder, analisis yang digunakan yaitu metode Water QualityIndex (WQI) dan analisis kesesuaian serta analisis daya dukung kawasan. Pengambilan data primer dilakukan di 11 stasiun berdasarkan titik kemunculan hiu paus selama tahun 2013 - 2015. Hasil analisis Water Quality Index(WQI) menunjukkan bahwa kondisi perairan Kwatisore baik air laut maupun tawar tergolong normal atau belum tercemar. Hasil perbandingan baku mutu air laut untuk wisata bahari dan biota laut menunjukkan bahwa perairan Kwatisore sesuai untuk dijadikan wisata bahari dan habitat biota laut seperti hiu paus. Penentuan waktu terbaik dalam melihat hiu paus adalah ketika fase bulan baru atau pada minggu 1 dan 2 awal bulan. Untuk analisis kesesuaian kawasan untuk wisata melihat hiu paus menunjukkan bahwa stasiun 1, 4, 7, 8, 9 dan 11 termasuk dalam kriteria S1 atau sangat sesuai,sedangkan stasiun 2, 3, 5, 6 dan 10 termasuk S2 atau sesuai sebagai lokasi melihat hiu paus. Hasil perhitungan nilai daya dukung kawasan (DDK) mencapai 108 wisatawan/hari.
\end{abstract}

Kata Kunci : Hiu Paus, Kwatisore, Daya Dukung Kawasan, Kesesuaian Kawasan, Wisata Bahari

\begin{abstract}
This research was conducted in the Kwatisore waters, Cenderawasih Bay National Park, Nabire district. This research was to determine the suitability of water environmental condition and carrying capacity of the region in supporting the development of whale shark's tourism. Using the cross section method, the source of the data was from the primary data and secondary. The data was analyzed by the method of Water Quality Index, suitability analysis, and analysis of carrying capacity of the region. The primary data was done in 11 stations by the point of emergence of the whale shark during $2013-2015$. The results of the analysis of Water Quality Index was indicating that Kwatisore water conditions both seawater and freshwater classified as normal or not yet contaminated. The comparison sea water quality standard for marine tourism and marine life shows that the waters Kwatisore suitable to be used as marine tourism and marine habitats such as whale sharks. The best time to see the whale sharks is when the new moon phase or at the 1 st and the 2 nd weeks every month. To analyze of the suitability of the area for whale sharks tourism shows that the stations $1,4,7$, 8, 9 and 11 are classified in the criteria S1 or very appropriate. Whereas, the stations 2, 3, 5, 6 and 10 are classified in the criteria S2 or suitable as a location for whale sharks tourism. The results of calculation of the carrying capacity whale shark tourism was reaching 108 tourists/day.
\end{abstract}

Keywords : Carrying Capacity of Region, Kwatisore, Marine Tourism, Region Compliance, Whale Sharks, Water Quality Index 


\section{Pendahuluan}

Sektor wisata dalam beberapa dekade terakhir berkembang dengan sangat pesat seiring dengan kemajuan ilmu pengetahuan dan teknologi yang memudahkan para wisatawan untuk menentukan destinasi wisatanya.Kondisi tersebut dapat dijadikan peluang bagi daerah yang memiliki potensi wisata. Pemanfaatan potensi wisata akan memberikan dampak dalam meningkatkan pendapatan daerah dan kesejahteraan masyarakat terutama bagi daerah yang memiliki potensi yang tidak dimiliki oleh daerah lain (Tambunan dkk, 2013). Indonesia merupakan negara yang memiliki keanekaragaman hayati yang sangat tinggi terutama keanekaragaman bahari disetiap wilayahnya.Salah satu wilayah di Indonesia yang memiliki potensi yang sangat besar dalam pengembangan destinasi wisata adalah wilayah Taman Nasional Teluk Cenderawasih.

Sebagai taman nasional laut, Teluk Cenderawasih memiliki potensi ekologi yang sangat besar terutama pada keanekaragaman sumberdaya pesisir. Kekayaan jenis ikan, penyu, mamalia laut, lamun serta moluska merupakan keunikan yang dimiliki oleh Teluk Cenderawasih (Pattiselanno dan Wanma, 2014). Keistimewaan lain dari Teluk Cenderawasih adalah keberadaan hiu paus (Rhincodon typus) yang dapat ditemukan disekitar perairan Teluk Cenderawasih.Kemunculan hiu paus di sekitar kawasan Taman Nasional Teluk Cenderawasih telah mendorong peningkatan kunjungan wisatawan lokal maupun domestik.Pada tahun 2011, pariwisata berbasis hiu paus sudah mulai berkembang di Taman Nasional Teluk Cenderawasih. Tercatat sudah ada dua resort di taman nasional Teluk Cenderawasih yang melayani wisatawan untuk melihat hiu paus, yakni Ahe Resort yang berbasis di Pulau Ahe dan kali Lemon Resort yang berbasis di Kali Lemon, Kwatisore.

Terlepas dari itu, jumlah hiu paus yang ditemukan di perairan Kwatisore mulai berkurang dengan ditandai angka kemunculannya yang berkurang.Kerentanan penurunan populasi hiu paus menjadi hal yang dikhawatirkan oleh pengelola Taman Nasional Teluk Cenderawasih dalam mengembangkan wisata hiu paus. Ukuran yang besar, pertumbuhan, dan pencapaian usia matang gonad yang lambat, menyebabkan hiu paus sangat rentan terhadap ancaman (Fajrina 2014 dalam Himawan 2015). Disisi lain pemanfaatan hiu paus sebagai daya tarik di Taman Nasional Teluk Cenderawasih dapat meningkatkan kunjungan wisatawan. Maka dari itu, dibutuhkan strategi pengelolaan berkelanjutan yang menerapkan konsep pelestarian yang modern, yakni pelestarian dan pemanfaatan sumberdaya bumi secara bijaksana, bukan hanya sekedar melindungi yang menutup peluang pemanfaatan (MacKinnon et al 1990 dalam Winara dan Mukhtar 2011).

Hal yang paling utama dalam konsep pemanfaatan sumberdaya adalah kesesuaian sumberdaya dan daya dukung yang dapat mendukung kegiatan wisata bahari (Hutabarat dkk 2009). Oleh karena itu,diperlukan penelitian dasar secara ilmiah mengenai analisis kesesuaian dan daya dukung lingkungan Teluk Cenderawasih untuk mengetahui pemanfaatan ruang yang sesuai dan daya dukung kawasan dalam upaya pengembangan Taman Nasional Teluk Cenderawasih sebagai daerah tujuan wisata hiu paus di Indonesia.

\section{Bahan dan Metode}

Penelitian ini dilaksanakan di kawasan Perairan Kwatisore, Kabupaten Nabire pada bulan Mei - September 2016.Penentuan stasiun penelitian berdasarkan data sebaran letak bagan dan kemunculan hiu paus selama tahun 2013 - 2015.Letak bagan dengan kemunculan hiu paus erat kaitannya dikarenakan bagan merupakan wadah yang dijadikan oleh hiu paus di perairan Kwatisore untuk mencari makan dan bermain (Suruan dkk, 2017). Jumlah stasiun penelitian ini sebanyak 11 titik dimana koordinat lokasinya ditentukan dengan menggunakan GPS. 


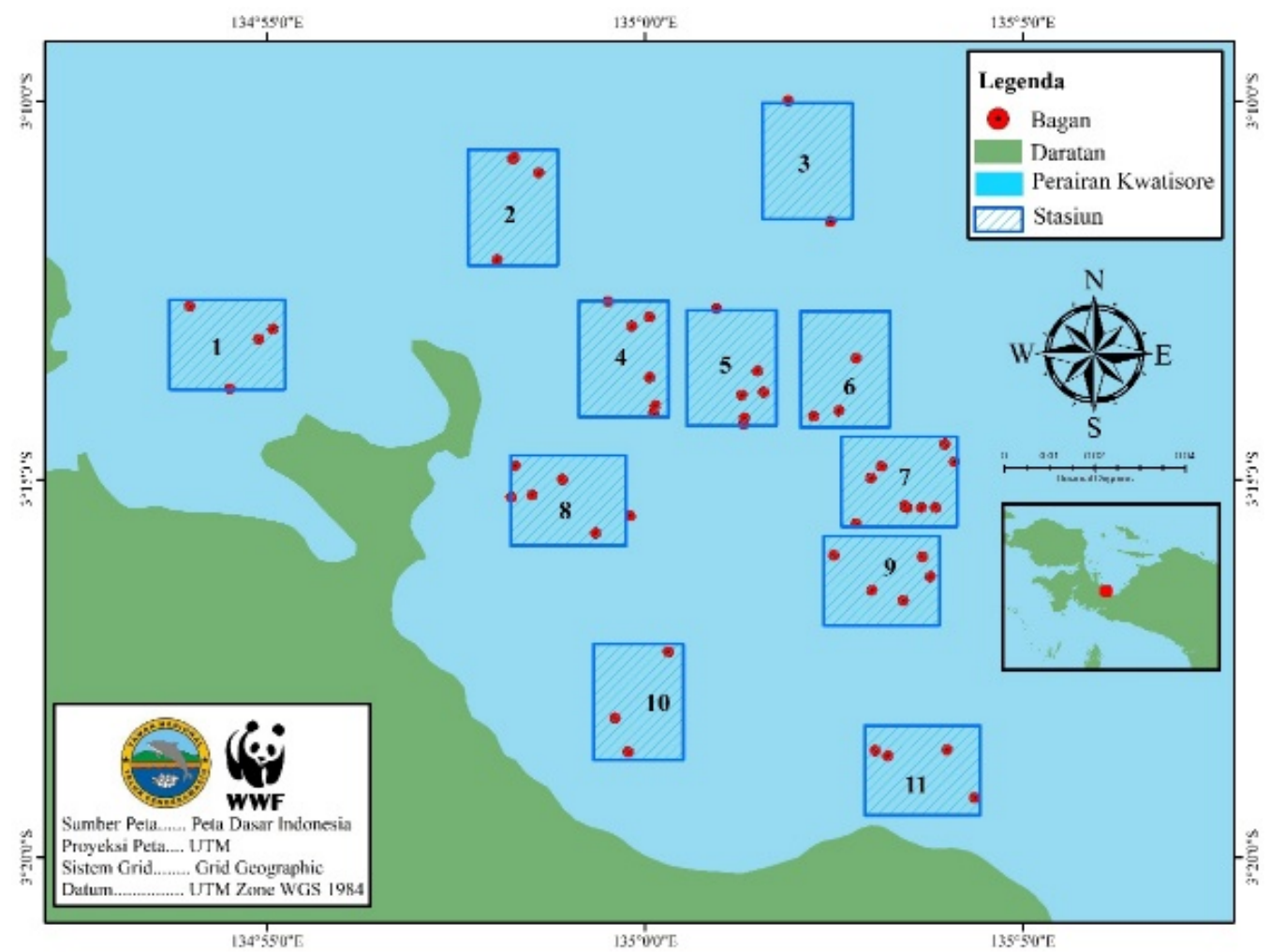

Gambar 1. Stasiun Penelitian

Figure 1. Research Station

\section{Pengamatan Hiu Paus}

Pengamatan Hiu Paus dilakukan untuk mengetahui karakteristik dan tingkah laku hiu paus selama agregasi.Pengamatan ini meliputi waktu kemunculan hiu paus, tingkah laku ketika beragregasi, jumlah hiu paus yang beragregasi di stasiun penelitian, dan ukuran hiu paus serta parameter lingkungan seperti suhu, salinitas, kecerahan dan pH.Pengamatan ini bertujuan untuk melihat kondisi lingkungan ketika hiu paus beragregasi dan muncul di permukaan.

Pengamatan hiu paus selama beragregasi dilakukan dengan berenang tepat disamping hiu paus dan membandingkan ukuran hiu paus dengan tinggi tubuh di bagan-bagan yang beroperasi (Himawan 2015). Pemilihan lokasi bagan sebelumnya dilakukan dengan menentukan titik koordinat bagan menggunakan GPS, wawancara dengan nelayan bagan mengenai informasi sekitar kemunculan hiu paus di bagan tersebut serta mengamati tingkah laku hiu paus selama beragregasiterhadap bagan posisi kemunculan hiu paus meliputi kordinat, nama bagan, ukuran bagan dan kondisi kelayakan bagan.

\section{Kualitas Lingkungan Perairan}

Pengukuraran kualitas air laut dilakukan selama pengamatan hiu paus di lokasi penelitian. Parameter yang diukur adalah kecerahan, salinitas, suhu, $\mathrm{pH}$, oksigen terlarut (DO), ammonia, fosfat, nitrat, sianida, sulfide dan logam berat seperti kromium (Cr), arsen (As), kadmium (Cd), tembaga $(\mathrm{Cu})$, timbal $(\mathrm{Pb})$, seng $(\mathrm{Zn})$ dan nikel (Ni). Data tersebut kemudian dibandingkan dengan Keputusan Menteri Lingkungan Hidup No. 51 Tahun 2004 tentang baku mutu air laut untuk wisata bahari dan biota laut. Selain itu dilakukan pengujian kualitas air tawar yang biasa digunakan wisatawan untuk air minum dan air bilas. Parameter yang diukur adalah bau, warna, total zat padat terlarut, kekeruhan, rasa, suhu, nitrit, nitrat, sianida, kromium $(\mathrm{Cr})$, cadmium, $(\mathrm{Cd})$, arsen (As), fluor, aluminium, besi, kesadahan, khlorida, mangan, $\mathrm{pH}$, seng, sulfat, tembaga dan ammonia. Prosedur pengujian berdasarkan SNI 01-3554-2006. Kemudian data tersebut dibandingkan dengan Peraturan Menteri 
Kesehatan No. 492/Menkes/Per/VI/2010 tentang persayaratan kualitas air minum.

Data kualitas air yang diperoleh dari penelitian ini baik air laut maupun air tawar dianalisis dengan menggunakan uji Water Quality Index Calculator. Uji Water Quality Index Calculator ini dilakukan dengan menjumlahkan nilai index setiap parameter yang diukur dengan kemudian dibandingkan dengan Water Quality Index Legend Tabel 1. Untuk mendapatkan nilai index setiap parameternya dapat diakses pada website www.water-research.net. Parameter yang dihitung adalah oksigen terlarut, Koliform Fecal, pH, BOD, perubahan suhu, total pospat, nitrat, kekeruhan dan TSS.

Tabel 1. Indeks Kualitas Air

Table 1.Water Quality Index Legend

\begin{tabular}{cc}
\hline Range & Quality \\
\hline $90-100$ & Excellent \\
$70-90$ & Good \\
$50-70$ & Medium \\
$25-50$ & Bad \\
$0-25$ & Very Bad \\
\hline
\end{tabular}

\section{Penilaian Kesesuaian Wisata Hiu Paus}

Kegiatan wisata yang akan dikembangkan hendaknya disesuaikan dengan potensi sumberdaya dan peruntukannya. Setiap kegiatan wisata mempunyai persyaratan sumberdaya dan lingkungan yang sesuai obyek wisata yang akan dikembangkan. Rumus yang digunakan untuk kesesuaian wisata pantai dan wisatabahari adalah (Yulianda 2007):

$$
\mathrm{IKW}=\left(\Sigma \mathrm{N}_{\mathrm{i}} / \mathrm{N}_{\text {maks }}\right) \times 100 \%
$$

Keterangan:

IKW = Indeks Kesesuaian Wisata
$\mathrm{Ni}=$ Nilai parameter ke-i

(Bobot x Skor)

Nmaks $=$ Nilai maksimum dari kategori wisata

Penentuan kesesuaian berdasarkan perkalian skor dan bobot yang diperoleh dari setiap parameter.Kesesuaian kawasan dilihat dari tingkat persentase kesesuaian yang diperoleh penjumlah nilai dari seluruh parameter.Kesesuaian wisata melihat hiu paus mempertimbangkan 3 parameter dengan 4 klasifikasi penilaian. Parameter kesesuaian wisata melihat hiu paus antara lain: kedalaman perairan, kecepatan arus, kedalaman agregasi hiu paus, lama agregasi hiu paus, jumlah hiu paus, dan ukuran hiu paus (Tabel 2).

Tabel 2.Matriks Kesesuaian Kawasan Wisata Hiu Paus

Table 2. Suitable Zone Matrix for Whale Shark Tourism

\begin{tabular}{ccccccccccc}
\hline No & Parameter & Bobot & $\begin{array}{c}\text { Kategori } \\
\text { S1 }\end{array}$ & Skor & $\begin{array}{c}\text { Kategori } \\
\text { S2 }\end{array}$ & Skor & $\begin{array}{c}\text { Kategori } \\
\text { S3 }\end{array}$ & Skor & $\begin{array}{c}\text { Kategori } \\
\text { N }\end{array}$ & Skor \\
\hline 1 & $\begin{array}{l}\text { Kecerahan } \\
\text { Perairan (m) }\end{array}$ & 5 & $>9$ & 4 & $>6-9$ & 3 & $>3-6$ & 2 & $<3$ & 1 \\
2 & $\begin{array}{l}\text { Kecepatan } \\
\text { arus (m/s) }\end{array}$ & 3 & $0-0,17$ & 4 & $0,17-0,34$ & 3 & $0,34-0,51$ & 2 & $>0,51$ & 1 \\
& $\begin{array}{l}\text { Intensitas } \\
\text { agregasi hiu } \\
\text { paus (x } \\
\text { sebulan) }\end{array}$ & 5 & $>10$ & 4 & $>5-10$ & 3 & $1-5$ & 2 & 0 & 1 \\
\hline
\end{tabular}

Sumber : modifikasi dari Yulianda (2007)

Keterangan:

$\mathrm{S} 1$ = Sangat sesuai, dengan nilai $80-100 \%$

S3 = Sesuai bersyarat, dengan nilai $35-<60 \%$

$\mathrm{S} 2=$ Cukup sesuai, dengan nilai $60-<80 \%$

$\mathrm{N}=$ Tidak sesuai, dengan nilai $<35 \%$

\section{Penghitungan Daya Dukung Kawasan}

Analisa daya dukung ditujukan pada pengembangan wisata bahari dengan memanfaatkan potensi sumberdaya pesisir, pantai dan pulau-pulau kecil secara lestari.Mengingat pengembangan wisata 
bahari tidak bersifat mass tourism, mudah rusak dan ruang untuk pengunjung sangat terbatas, maka perlu penentuan daya dukung kawasan.

Metode yang diperkenalkan untuk menghitung daya dukung pengembangan ekowisata alam adalah dengan menggunakan konsep Daya Dukung Kawasan (DDK).DDK adalah jumlah maksimum pengunjung yang secara fisik dapat ditampung di kawasan yang disediakan pada waktu tertentu tanpa menimbulkan gangguan pada alam dan manusia.Untuk menghitung daya dukung kawasan, metode yang biasanya digunakan adalah metode Yulianda (2007).Oleh karena itu, digunakan metode Yulianda (2007) dengan modifikasi satuan lahan dengan jumlah bagan yang digunakan.Itu dikarenakan pada wisata hiu paus, luasan lahan yang digunakan tergantung berapa banyak bagan yang dapat ditemukannya hiu paus. Rumus menghitung DDK tersebut adalah :

$$
\mathrm{DDK}=\mathrm{K} \times \mathrm{nB} \times(\mathrm{Wt} / \mathrm{Wp})
$$

Keterangan :

DDK = Daya Dukung Kawasan

$\mathrm{K}=$ Potensi ekologis pengunjung per satuan unit area (6)

$\mathrm{nB}=$ Jumlah unit bagan ditemukannya hiu paus
$\mathrm{Wt}=$ Waktu yang disediakan oleh kawasan untuk melihat hiu paus dalam satu hari
$\mathrm{Wp}=$ Waktu yang dihabiskan oleh pengunjung untuk melihat hiu paus (1 jam)

\section{Analisis Spasial}

Analisis spasial yang digunakan pada skripsi ini yaitu berupa peta zonasi wilayah untuk wisata bahari.Peta ini digunakan untuk menginterpretasikan data kesesuaian wilayah menjadi sebuah peta zonasi sehingga daerahdaerah yang cocok untuk dimanfaatkan untuk lokasi wisata bahari dapat tergambarkan secara jelas dan dapat digunakan oleh khalayak umum maupun pemerintah untuk penggunaan data secara lebih lanjut.Pembuatan peta zonasi diolah menggunakan software ArcMap 10.1.

\section{Hasil dan Pembahasan}

\section{Pengamatan Kemunculan Hiu Paus}

Kemunculan hiu paus di permukaan perairan Kwatisore erat kairtannya dengan keberadaan bagan.Dimana bagan ini merupakan tempat mencari makan dan bermain hiu paus.Selain itu, bagan merupakan alat tangkap bagi ikanikan pelagis kecil yang merupakan makanan hiu paus.Berikut adalah gambar letak bagan berdasarkan waktu yang beroperasi disekitar perairan Kwatisore (Gambar

2).

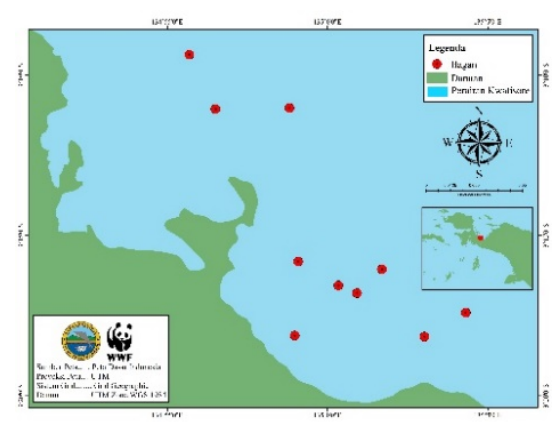

Gambar 2a. Letak Bagan pada Tanggal 23 Mei 2016 /

Picture 2a. Bagan Position on 23 of Mei 2016 


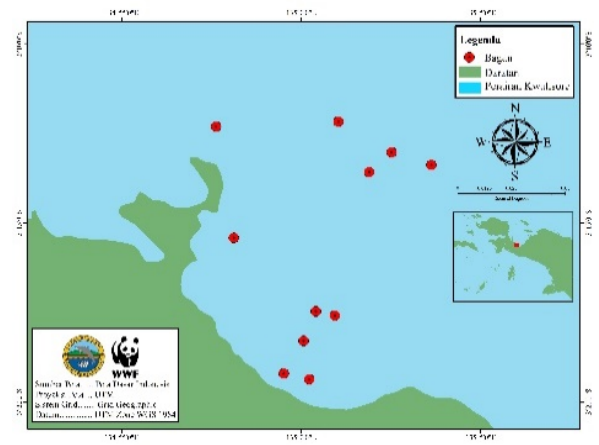

Gambar 2b. Letak Bagan pada Tanggal 30 Mei 2016

Picture 2b. Bagan Position on 30 of Mei 2016

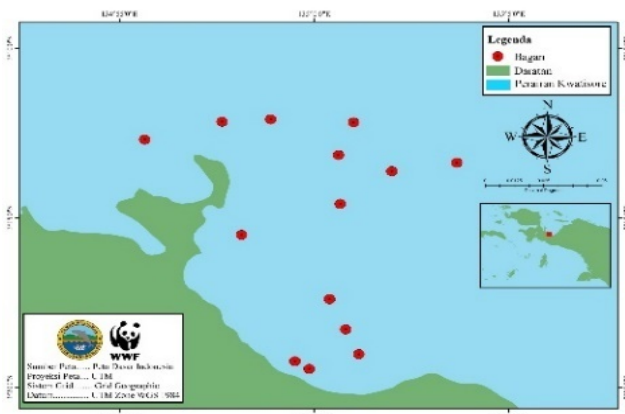

Gambar 2c. Letak Bagan pada Tanggal 6 Juni 2016

Picture 2c. Bagan Position of 6 June 2016

Berdasarkan hasil pengambilan titik kordinat bagan selama 1 bulan, jumlah bagan mengalami perubahan setiap waktunya.Pada tanggal 23 Mei 2016, jumlah bagan yang beroperasi sekitar 9 bagan. Kemudian pada tanggal 30 Mei 2016 jumlah bagan bertambah menjadi 11 bagan dan pada tanggal 6 juni 2016 jumlah bagan yang beroperasi sekitar 15 bagan. Hasil wawancara dengan nelayan bagan menyebutkan bahwa faktor utama yang menentukan perubahan jumlah bagan setiap waktunya adalah faktor cuaca dan faktor hasil tangkapan. Ketika gelombang laut tinggi dan cuaca dilaut tidak mendukung, maka kebanyakan bagan tidak akan beroperasi dan memilih untuk mendarat. Kemudian ketika cuaca sudah mendukung, bagan kemudian akan melaut kembali.

Waktu pengamatan dilakukan secara tidak menentu, tergantung ada atau tidaknya kemunculan hiu paus.Hal ini dikarenakan ketika waktu penelitian di bulan Mei hingga bulan Juni 2016, kemunculan hiu paus tidak muncul sesering bulan-bulan sebelumnya.Kondisi cuaca dan musim menyebabkan intensitas kemunculan hiu paus berkurang. Salah satu faktor yang menjadikan kurangnya intensitas kemunculan hiu paus ke permukaan adalah kurangnya pasokan makanan hiu paus yakni ikan puri di perairan Kwatisore.Fase bulan dapat mempengaruhi

Tabel 3. Periode Kemunculan Bulan

Table 3. Month Coming Period

\begin{tabular}{ccc}
\hline Tanggal & $\begin{array}{c}\text { Durasi Kemunculan } \\
\text { Bulan }\end{array}$ & Keterangan \\
\hline 16 Mei - 24 Mei 2016 & $8.5-12.5$ & Terang (Purnama) \\
25 Mei - 31 Mei 2016 & $4.5-8$ & Semi Terang (Kuartal Kedua)
\end{tabular}




\begin{tabular}{ccc}
\hline Tanggal & $\begin{array}{c}\text { Durasi Kemunculan } \\
\text { Bulan }\end{array}$ & Keterangan \\
\hline 1 Juni - 8 Juni 2016 & $0-4.5$ & Gelap (Bulan Baru) \\
9 Juni - 15 Juni 2016 & $4.5-8$ & Semi Terang (Kuartal Pertama) \\
\hline Sumber : https://ind.timegenie.com/moon_phases/city/idnbx &
\end{tabular}

Pengamatan mengenai fase bulan ini dapat memberikan rekomendasi waktu terbaik untuk pengelola dalam merencenakan waktu wisata hiu paus. Waktu yang terbaik untuk berwisata melihat hiu paus adalah pada fase bulan gelap atau bulan baru yakni pada awal bulan.Sehingga para wisatawan dapat melihat hiu paus setiap harinya.

Tingkah laku hiu paus ketika beragregasi yaitu hiu paus berenang dengan lambat mengitari bagan dengan kondisi mulut yang terbuka. Posisi mulut hiu paus ini mengindikasikan bahwa hiu paus sedang menyaring air laut untuk mendapatkan makanan berupa plankton dan hewan-hewan kecil laut lain seperti ikan puri. Hiu paus yang merupakan hewan jinak biasanya muncul bergerombol dengan jumlah 2-7 ekor.Kebiasaannya ini sangat disukai oleh wisatawan, karena wisatawan lebih menyukai berenang bersama hiu paus dalam jumlah yang banyak.

Panjang tubuh hiu paus yang ditemukan adalah sekitar 3-10 m, sedangkan menurut Himawan (2015), ukuran hiu paus yang ditemukan di perairan Kwatisore adalah 3-6.9 $\mathrm{m}$. Panjang tubuh ini menandakan bahwa hiu paus yang ditemukan merupakan hiu paus yang belum matang gonad dan berumur kurang dari 30 tahun. Ukuran hiu paus saat lahir berkisar 55 dan $64 \mathrm{~cm}$. Hiu paus berada pada masa belum matang pada ukuran 2.99 $\mathrm{m}$, kemudian pada masa remaja ukuran tubuhnya sekitar 3.90-5.40 $\mathrm{m}$ dan masa dewasa ketika berukuran 7.05-10.26 meter. Sedangkan hiu paus betina mengalami masa belum matang ketika berukuran $3.40-7.60$ meter dan masa dewasa ketika berukuran sekitar 12 meter (Compagno 2002 dalam Himawan 2015).

\section{Kualitas Air Laut dan Air Tawar Perairan Kwatisore}

Pengukuran parameter lingkungan sebagai faktor yang sangat penting dalam kegiatan wisata melihat hiu paus dilakukan secara insitu dan eksitu.Hasil pengukuran parameter lingkungan secara insitu disajikan dalam Tabel 4.

Tabel 4. Data Parameter Fisika dan Kimia Perairan Laut Kwatisore

Table 4. Parameter Physics and Chemisty Data in Kwatisore water

\begin{tabular}{|c|c|c|c|c|c|c|c|c|c|c|c|c|c|}
\hline \multirow[b]{2}{*}{ Paramater } & \multirow[b]{2}{*}{ Satuan } & \multirow[b]{2}{*}{$\begin{array}{l}\text { Baku } \\
\text { Mutu }\end{array}$} & \multicolumn{11}{|c|}{ Stasiun Pengamatan } \\
\hline & & & St1 & St2 & St3 & St4 & St5 & St6 & St7 & St8 & St9 & St10 & St11 \\
\hline Suhu & ${ }^{0} \mathrm{C}$ & - & 30 & 30 & 31 & 30 & 30 & 31 & 31 & 30 & 30 & 32 & 32 \\
\hline Salinitas & $\%$ & - & 30 & 30 & 30 & 29 & 30 & 30 & 30 & 30 & 28 & 30 & 28 \\
\hline Kec. Arus & $\mathrm{cm} \mathrm{s}^{-1}$ & - & 0.15 & 0.35 & 0.44 & 0.3 & 0.35 & 0.4 & 0.35 & 0.35 & 0.51 & 0.3 & 0.14 \\
\hline Kecerahan & $\mathrm{m}$ & $>5$ & 17.55 & 11.7 & 18.05 & 10.25 & 12.65 & 18.15 & 16.1 & 10.4 & 16.6 & 16.4 & 11.23 \\
\hline $\mathrm{pH}$ & - & - & 8 & 8 & 8 & 7,8 & 8 & 8 & 8 & 7,8 & 7,9 & 8 & 8 \\
\hline
\end{tabular}

Selain parameter diatas, terdapat beberapa parameter lain yang diukur secara eksitu dan dibandingkan dengan baku mutu untuk wisata bahari.Parameter yang dihitung hanya pada perairan di stasiun yang memiliki kemunculan hiu paus terbanyak yaitu pada stasiun 7 tepatnya pada kordinat $134.95609^{\circ}$ dan $-3.2253^{\circ}$. Hasil pengukuran kemudian dibandingkan dengan baku mutu air laut untuk wisata bahari dan biota laut (Tabel 5). 
Donny Juliandri Prihadi : Daya Dukung Lingkungan dan Analisis Kesesuaian pada Wisata Hiu Paus (Rhincodon typus) di Taman Nasional Teluk Cenderawasih, Kabupaten Nabire

Tabel 5. Perbandingan Parameter Lingkungan Air Laut dengan Baku Mutu untuk Wisata Bahari dan Biota Laut /

Table 5. A Comparison of the Environmental Parameters of Seawater with a Raw Quality to Marine Tourism and Marine Life

\begin{tabular}{|c|c|c|c|c|c|c|c|}
\hline \multirow{2}{*}{ No } & \multirow{2}{*}{ Parameter } & \multirow{2}{*}{ Satuan } & \multirow{2}{*}{$\begin{array}{c}\text { Hasil } \\
\text { Pengukura } \\
\text { n }\end{array}$} & \multicolumn{2}{|c|}{ Baku Mutu } & \multicolumn{2}{|c|}{$\begin{array}{c}\text { Hasil } \\
\text { Perbandingan }\end{array}$} \\
\hline & & & & Wisata Bahari & Biota Laut & $\begin{array}{l}\text { Wisata } \\
\text { Bahari }\end{array}$ & $\begin{array}{c}\text { Biota } \\
\text { Laut }\end{array}$ \\
\hline 1 & Warna & Pt.co & $\begin{array}{c}\text { Tidak } \\
\text { Berwarna } \\
\text { Tidak }\end{array}$ & 30 & - & $\mathrm{S}$ & $\mathrm{S}$ \\
\hline 2 & $\mathrm{Bau}$ & & berbau & Tidak Berbau & Tidak Berbau & S & $\mathrm{S}$ \\
\hline 3 & Kecerahan & M & 16.1 & $>6$ & Alami & $\mathrm{S}$ & $\mathrm{S}$ \\
\hline 4 & Kekeruhan & NTU & 9.1 & 5 & $<5$ & $\mathrm{TS}$ & $\mathrm{TS}$ \\
\hline 5 & TSS & $\mathrm{mg} / 1$ & 1.6 & 20 & 20 & $\mathrm{~S}$ & $\mathrm{~S}$ \\
\hline 6 & Suhu & ${ }^{\circ} \mathrm{C}$ & 6.2 & Alami & Alami & $\mathrm{S}$ & $\mathrm{S}$ \\
\hline 7 & Sampah & - & Nihil & Nihil & Nihil & $\mathrm{S}$ & $\mathrm{S}$ \\
\hline 8 & Lapisan Minyak & - & Nihil & Nihil & Nihil & $\mathrm{S}$ & $\mathrm{S}$ \\
\hline 9 & $\mathrm{pH}$ & - & 8 & $7-8.5$ & $7-8.5$ & $\mathrm{~S}$ & $\mathrm{~S}$ \\
\hline 10 & Salinitas & $\%$ & 30 & Alami & Alami & $\mathrm{S}$ & $\mathrm{S}$ \\
\hline 11 & Oksigen Terlarut & $\mathrm{mg} / \mathrm{l}$ & 8.4 & $>5$ & $>5$ & $\mathrm{~S}$ & $\mathrm{~S}$ \\
\hline 12 & BOD & $\mathrm{mg} / \mathrm{l}$ & 6.2 & 10 & 20 & $\mathrm{~S}$ & $\mathrm{~S}$ \\
\hline 13 & Ammonia & $\mathrm{mg} / 1$ & 0.001 & Nihil* & 0.3 & S & S \\
\hline 14 & Fosfat & $\mathrm{mg} / \mathrm{l}$ & 0.006 & 0.015 & 0.015 & $\mathrm{~S}$ & $\mathrm{~S}$ \\
\hline 15 & Nitrat & $\mathrm{mg} / \mathrm{l}$ & 0.145 & 0.008 & 0.008 & $\mathrm{TS}$ & $\mathrm{TS}$ \\
\hline 16 & Sianida & $\mathrm{mg} / 1$ & $<0.002$ & - & 0.5 & - & $\mathrm{S}$ \\
\hline 17 & Sulfida & $\mathrm{mg} / \mathrm{l}$ & $<0.02$ & Nihil* & 0.01 & $\mathrm{~S}$ & $\mathrm{~S}$ \\
\hline 18 & Fenol & $\mathrm{mg} / 1$ & $<0.003$ & Nihil* & 0.002 & $\mathrm{~S}$ & $\mathrm{BD}$ \\
\hline 19 & Surfaktan & $\mathrm{mg} / 1$ & 0.263 & 0.001 & 1 & $\mathrm{TS}$ & $\mathrm{S}$ \\
\hline 20 & Minyak & $\begin{array}{c}\mathrm{mg} / 1 \\
\mathrm{MPN} / 100\end{array}$ & $<0.1$ & 1 & 1 & $\mathrm{~S}$ & $\mathrm{~S}$ \\
\hline 21 & Koliform & $\mathrm{ml}$ & 252.88 & 1000 & 1000 & $\mathrm{~S}$ & $\mathrm{~S}$ \\
\hline 22 & Kromium & $\mathrm{mg} / \mathrm{l}$ & $<0.006$ & 0.002 & 0.005 & $\mathrm{BD}$ & $\mathrm{BD}$ \\
\hline 23 & Kadmium & $\mathrm{mg} / \mathrm{l}$ & $<0.001$ & 0.002 & 0.001 & $\mathrm{~S}$ & $\mathrm{~S}$ \\
\hline 24 & Tembaga & $\mathrm{mg} / \mathrm{l}$ & $<0.001$ & 0.05 & 0.008 & $\mathrm{~S}$ & $\mathrm{~S}$ \\
\hline 25 & Timbal & $\mathrm{mg} / \mathrm{l}$ & $<0.005$ & 0.005 & 0.008 & S & $\mathrm{S}$ \\
\hline 26 & Seng & $\mathrm{mg} / 1$ & 0.033 & 0.095 & 0.05 & $\mathrm{~S}$ & $\mathrm{~S}$ \\
\hline 27 & Nikel & $\mathrm{mg} / \mathrm{l}$ & $<0.001$ & 0.075 & 0.05 & $\mathrm{~S}$ & $\mathrm{~S}$ \\
\hline
\end{tabular}

Ket : * Nihil adalah tidak terdeteksi dengan batas deteksi alat yang digunakan (sesuai dengan metode yang digunakan)

$\mathrm{S}=$ Sesuai

$\mathrm{TS}=$ Tidak Sesuai

$\mathrm{BD}=$ Belum Diketahui

Berdasarkan Tabel 5, perairan Kwatisore tergolong perairan yang sesuai dengan baku mutu untuk wisata bahari dan habitat biota laut. Untuk baku mutu wisata bahari, 22 dari 26 parameter sudah sesuai dengan baku mutu dan 3 parameter tidak sesuai dikarenakan melebihi baku mutu serta 1 parameter belum diketahui kesesuaiannya. Kesesuaian dari parameter yang terukur mencapai $84.61 \%$. Untuk baku mutu biota laut, 23 dari 27 
parameter yang terukur sudah sesuai dengan baku mutu. Hanya 2 parameter saja yang tergolong tidak sesuai dan 2 parameter yang masih belum bisa ditentukan. Kesesuaian dari parameter yang terukur mencapai $85.18 \%$.
Selain membandingkan parameter lingkungan dengan baku mutu air laut, parameter yang diukur juga dianalisis dengan uji Water Quality Index. Hasil analisis menggunakan uji ini disajikan dalam Tabel 6.

Tabel 6. Hasil Uji Water Quality Index untuk Air Laut

Table 6. The Test Results of Water Quality Index for Sea Water

\begin{tabular}{|c|c|c|c|c|}
\hline No & Parameter & Satuan & $\begin{array}{c}\text { Hasil } \\
\text { Pengukuran }\end{array}$ & Skor WQI \\
\hline 1 & Oksigen Terlarut & $\%$ & 8.4 & 6 \\
\hline 2 & Total Koliform & $\mathrm{Jml} / 100 \mathrm{~mL}$ & 252.88 & 35 \\
\hline 3 & $\mathrm{pH}$ & - & 8 & 84 \\
\hline 4 & BOD & $\mathrm{mg} / 1$ & 6.2 & 50 \\
\hline 5 & Perubahan Suhu & ${ }^{\circ} \mathrm{C}$ & 3 & 81 \\
\hline 6 & Total Fosfat & $\mathrm{mg} / \mathrm{l}$ & 0.006 & 100 \\
\hline 7 & Nitrat & $\mathrm{mg} / \mathrm{l}$ & 0.145 & 97 \\
\hline 8 & Kekeruhan & NTU & 8.4 & 79 \\
\hline 9 & TSS & $\mathrm{mg} / 1$ & 1.6 & 79 \\
\hline \multicolumn{4}{|c|}{ Total Perhitungan WQI } & 53 \\
\hline
\end{tabular}

Hasil analisis kualitas air menggunakan standar air atau Water Quality Index (WQI) diketahui bahwa kondisi perairan Kwatisore adalah normal atau medium. Berdasarkan kategori ini, kualitas perairan Kwatisore dapat dikatakan masih belum tercemar, namun beberapa parameter perairan perlu diwaspadai karena melampaui ambang batas.Kondisi dari setiap parameter dapat dilihat dari skor WQI.Semakin tinggi skor WQI suatu parameter maka semakin baik kondisi parameter tersebut.Semakin rendah skor WQI suatu parameter maka semakin buruk kondisi parameter di perairan tersebut. Beberapa parameter yang harus diwaspadai adalah total koliform dan oksigen terlarut.

Penghitungan kualitas air tawar di perairan Kwatisore bertujuan untuk melihat kualitas air tawar yang biasanya digunakan oleh wisatawan sebagai air bersih untuk minum dan bilas. Sampel air yang digunakan diambil dari sungai kalilemon yang berada di sekitar Kalilemon Resort pada kordinat $134.0956^{\circ}$ dan $-3.2253^{\circ}$. Hasil pengukuran kualitas air kemudian dibandingkan dengan Peraturan Menteri Kesehatan Republik Indonesia No 416/MENKES/PER/IX/1990 tentang kualitas air bersih dan Peraturan Menteri Kesehatan No 492/MENKES/PER/IV/2010 tentang persyaratan kualitas air minum. Selain itu hasil pengukuran juga akan dianalisis dengan uji Water Quality Index (WQI). Nilai parameter lingkungan air tawar dan standar baku mutu air bersih disajikan pada Tabel 7.

Tabel 7. Perbandingan Parameter Lingkungan Air Tawar dengan Baku Mutu untuk Air Bersih dan Air Minum /

Table 7. A comparison of the parameters of the Freshwater Environment with Quality Raw for clean water and drinking water

\begin{tabular}{lllllll}
\hline \multirow{2}{*}{ Parameter } & \multirow{2}{*}{ Satuan } & Hasil Pengukuran & $\begin{array}{l}\text { Baku Mutu } \\
\text { Air Bersih }\end{array}$ & Air Minum & \multicolumn{2}{c}{ Air Bersih Perbandingan } \\
& & & Air Minum \\
\hline Warna & TCU & Tidak Berwarna & Tidak Berwarna & Tidak Berwarna & S & S \\
Bau & - & Tidak berbau & Tidak Berbau & Tidak Berbau & S & S \\
Kekeruhan & NTU & 9.1 & 5 & 5 & TS & TS \\
TDS & mg/l & 60 & 20 & 500 & TS & S
\end{tabular}


Donny Juliandri Prihadi : Daya Dukung Lingkungan dan Analisis Kesesuaian pada Wisata Hiu Paus (Rhincodon typus) di Taman Nasional Teluk Cenderawasih, Kabupaten Nabire

\begin{tabular}{|c|c|c|c|c|c|c|}
\hline \multirow{2}{*}{ Parameter } & \multirow{2}{*}{ Satuan } & \multirow{2}{*}{ Hasil Pengukuran } & \multicolumn{2}{|l|}{ Baku Mutu } & \multicolumn{2}{|c|}{ Hasil Perbandingan } \\
\hline & & & Air Bersih & Air Minum & Air Bersih & Air Minum \\
\hline Suhu & ${ }^{\circ} \mathrm{C}$ & 27 & Alami & Suhu Udara & $\mathrm{S}$ & S \\
\hline Rasa & - & Nihil & Nihil & Nihil & S & S \\
\hline $\mathrm{pH}$ & - & 7.15 & $6.5-9$ & $6.5-8.5$ & S & S \\
\hline Flourida & $\%_{0}$ & $<0.06$ & 1.5 & 1.5 & S & S \\
\hline Total Kromium & $\mathrm{mg} / 1$ & $<0.006$ & $>5$ & 0.05 & $\mathrm{~S}$ & S \\
\hline Kadmium & $\mathrm{mg} / \mathrm{l}$ & $<0.001$ & 10 & 0.003 & S & S \\
\hline Nitrit & $\mathrm{mg} / 1$ & 0.003 & 1 & 3 & $\mathrm{~S}$ & S \\
\hline Nitrat & $\mathrm{mg} / \mathrm{l}$ & 0.06 & 10 & 50 & S & S \\
\hline Sianida & $\mathrm{mg} / \mathrm{l}$ & $<0.002$ & 0.1 & 0.07 & S & S \\
\hline Besi & $\mathrm{mg} / 1$ & $<0.05$ & 1 & 0.3 & S & S \\
\hline Kesadahan & $\mathrm{mg} / \mathrm{l}$ & $<1.3$ & 500 & 500 & S & S \\
\hline Khlorida & $\mathrm{mg} / \mathrm{l}$ & 3.91 & 600 & 250 & S & S \\
\hline Mangan & $\mathrm{mg} / \mathrm{l}$ & $<0.01$ & 0.5 & 0.4 & $\mathrm{~S}$ & S \\
\hline Koliform & MPN/100ml & 40.89 & - & 0 & - & TS \\
\hline Sulfat & $\mathrm{mg} / \mathrm{l}$ & 5.75 & 400 & 250 & S & S \\
\hline Seng & $\mathrm{mg} / 1$ & $<0.01$ & 15 & 3 & S & S \\
\hline Tembaga & $\mathrm{mg} / \mathrm{l}$ & $<0.01$ & - & 2 & - & S \\
\hline Timbal & $\mathrm{mg} / \mathrm{l}$ & 0.012 & 0.05 & 0.008 & S & TS \\
\hline Ammonia & $\mathrm{mg} / \mathrm{l}$ & 0.004 & - & 1.5 & - & $\mathrm{S}$ \\
\hline $\begin{array}{r}\text { Keterangan : } \\
\mathrm{S} \\
\mathrm{TS} \\
\mathrm{BD}\end{array}$ & $\begin{aligned}- & =\text { Tidak ad } \\
& =\text { Sesuai } \\
& =\text { Tidak Se } \\
& =\text { Belum D }\end{aligned}$ & $\begin{array}{l}\text { a dalam baku mutu } \\
\text { suai } \\
\text { iketahui }\end{array}$ & & & & \\
\hline
\end{tabular}

Berdasarkan Tabel 7, sungai Kalilemon di perairan Kwatisore tergolong perairan dengan air yang sesuai dengan baku mutu untuk air bersih dan air minum. Untuk baku mutu air bersih, 18 dari 20 parameter yang diukur sudah sesuai dengan baku mutu dan 2 parameter tidak sesuai dikarenakan melebihi baku mutu. Kesesuaian dari parameter yang terukur mencapai $90.00 \%$. Untuk baku mutu air bersih, 20 dari 23 parameter yang terukur sudah sesuai dengan baku mutu. Hanya 2 parameter saja yang tergolong tidak sesuai dengan baku mutu. Kesesuaian dari parameter yang terukur mencapai $86.95 \%$. Dengan persentase kesesuaian yang sangat besar ini, air dari sungai Kalilemon dapat dikatakan baik untuk digunakan bilas bahkan air minum, meskipun dalam beberapa parameter masih melampuai baku mutu.

Selain membandingkan parameter lingkungan dengan baku mutu air bersih dan air minum, parameter yang diukur juga dianalisis dengan uji Water Quality Index. Hasil analisis menggunakan uji ini disajikan dalam

Tabel

Tabel 13. Hasil Uji Water Quality Index untuk Air Tawar

Table 13. The test results of Water Quality Index for fresh water

\begin{tabular}{ccccc}
\hline No & Parameter & Satuan & $\begin{array}{c}\text { Hasil } \\
\text { Pengukuran }\end{array}$ & Skor WQI \\
\hline 1 & Oksigen Terlarut & $\%$ oo & 10.6 & 7 \\
2 & Total Koliform & $\mathrm{Jml} / 100 \mathrm{~mL}$ & 40.89 & 55 \\
3 & $\mathrm{pH}$ & - & 7.15 & 91 \\
4 & $\mathrm{BOD}$ & $\mathrm{mg} / 1$ & 5.3 & 54
\end{tabular}




\begin{tabular}{ccccc}
\hline No & Parameter & Satuan & $\begin{array}{c}\text { Hasil } \\
\text { Pengukuran }\end{array}$ & Skor WQI \\
\hline 5 & Perubahan Suhu & ${ }^{\circ} \mathrm{C}$ & 2 & 85 \\
6 & Total Fosfat & $\mathrm{mg} / 1$ & 0.002 & 100 \\
7 & Nitrat & $\mathrm{mg} / 1$ & 0.06 & 97 \\
8 & Kekeruhan & $\mathrm{NTU}$ & 9.1 & 78 \\
9 & TSS & $\mathrm{mg} / 1$ & 2 & 80 \\
\hline \multicolumn{2}{c}{ Total Perhitungan WQI } \\
\hline
\end{tabular}

Kualitas air sungai Kalilemon di perairan Kwatisore berdasarkan Water Quality Index (WQI) menunjukan hasil normal (medium). Hasil WQI normal menunjukkan bahwa belum terjadi pencemaran yang dapat membahayakan lingkungan perairan.Hanya saja, walaupun belum terjadi pencemaran yang dapat membahayakan, parameterparameter tertentu seperti koliform menyebabkan air dari sungai ini tidak benarbenar baik untuk digunakan terutama untuk dikonsumsi.Sebab koliform dapat membahayakan kesehatan apabila masuk kedalam tubuh wisatawan.Keberadaan koliform mengindikasikan perairan sungai Kalilemon telah tercemar tinja (kotoran). Dibutuhkan penanganan untuk mengurangi jumlah koliform ataupun parameter lain yang melampaui batas yang dapat diterapkan sebelum air digunaka seperti penyaringan atau pemasakan.

\section{Kesesuaian Lahan Wisata Hiи Paus Perairan Kwatisore}

Hasil analisis kesesuaian kawasan wisata bahari dalam kategori wisata hiu paus mempertimbangkan tiga parameter dengan empat klasifikasi penilaian. Parameter kesesuaian wisata bahari kategori wisata hiu paus antara lain kecerahan perairan, kecepatan arus dan intensitas hiu paus beragregasi di sekitar stasiun. Setiap stasiun memiliki nilai kesesuaian kawasan wisata yang beragam. Hasil analisis kesesuaian kawasan wisata kategori wisata hiu paus dapat dilihat padaTabel

Tabel 8. Hasil Nilai IKW

Table 8. The Result Value Of The Tourism Suitable index

\begin{tabular}{ccc}
\hline Stasiun & Nilai IKW $(\%)$ & Tingkat Kesesuaian \\
\hline 1 & 80.77 & Sangat Sesuai \\
2 & 69.23 & Sesuai \\
3 & 69.23 & Sesuai \\
4 & 84.61 & Sangat Sesuai \\
5 & 78.85 & Sesuai \\
6 & 69.23 & Sesuai \\
7 & 88.46 & Sangat Sesuai \\
8 & 88.46 & Sangat Sesuai \\
9 & 88.46 & Sangat Sesuai \\
10 & 75 & Sesuai \\
11 & 80.77 & Sangat Sesuai \\
\hline
\end{tabular}

Berdasarkan indeks kesesuaian kawasan, lingkungan perairan Kwatisore sangatlah sesuai untuk dijadikan wisata hiu paus.Selain karena kemunculan hiu paus di perairan ini, kondisi lingkungan yang masih bersih sangat mendukung untuk dijadikan pengembangan kawasan wisata.Seperti kecerahan yang sangat tinggi yang mengindikasikan bahwa perairan Kwatisore belum tercemar dan aman untuk dijadikan tempat berenang untuk 
wisatawan. Selain itu kondisi kecepatan arus yang tidak terlalu besar yakni sekitar 0,14 $0,51 \mathrm{~ms}^{-1}$, aman dan tidak menyulitkan wisatawan dalam kegiatan berenang bersama hiu paus.Kondisi ini yang membuat 11 stasiun dalam penelitian ini tergolong sesuai dan sangat sesuai.Stasiun yang tergolong sangat sesuai yaitu stasiun 1, 4, 7, 8, 9 dan 11 sedangkan stasiun yang tergolong sesuai yaitu stasiun 2, 3, 5, 6 dan 10 (Gambar 3).

Tingkat kecerahan pada kawasan perairan Kwatisore sangatlah tinggi yakni $15 \mathrm{~m}$ hingga $20 \mathrm{~m}$. Ini menunjukan bahwa perairan tersebut memiliki jarang pandang yang sangat tinggi di perairan.Kondisi ini sangat mendukung kegiatan wisata untuk melihat hiu paus.Dengan jarak pandang yang tinggi, membantu wisatawan untuk melihat aktivitas hiu paus selama berenang dipermukaan.Dibandingkan dengan standar baku mutu air laut untuk wisata bahari yaitu kecerahan perairan $>6 \mathrm{~m}$, tingkat kecerahan pada perairan Kwatisore tergolong sangat sesuai untuk kegiatan wisata bahari. Tingginya kecerahan pada perairan ini disebabkan karena kondisi perairan yang masih alami dan sedikitnya sumber polutan yang masuk ke perairan.Polutan yang ada di perairan Kwatisore banyaknya berupa bongkahan-bongkahan kayu yang berasal dari hutan sekitar pantai yang tumbang dan terbawa hanyut ke perairan laut.Sehingga tidak terlalu mempengaruhi kecerahan perairan.

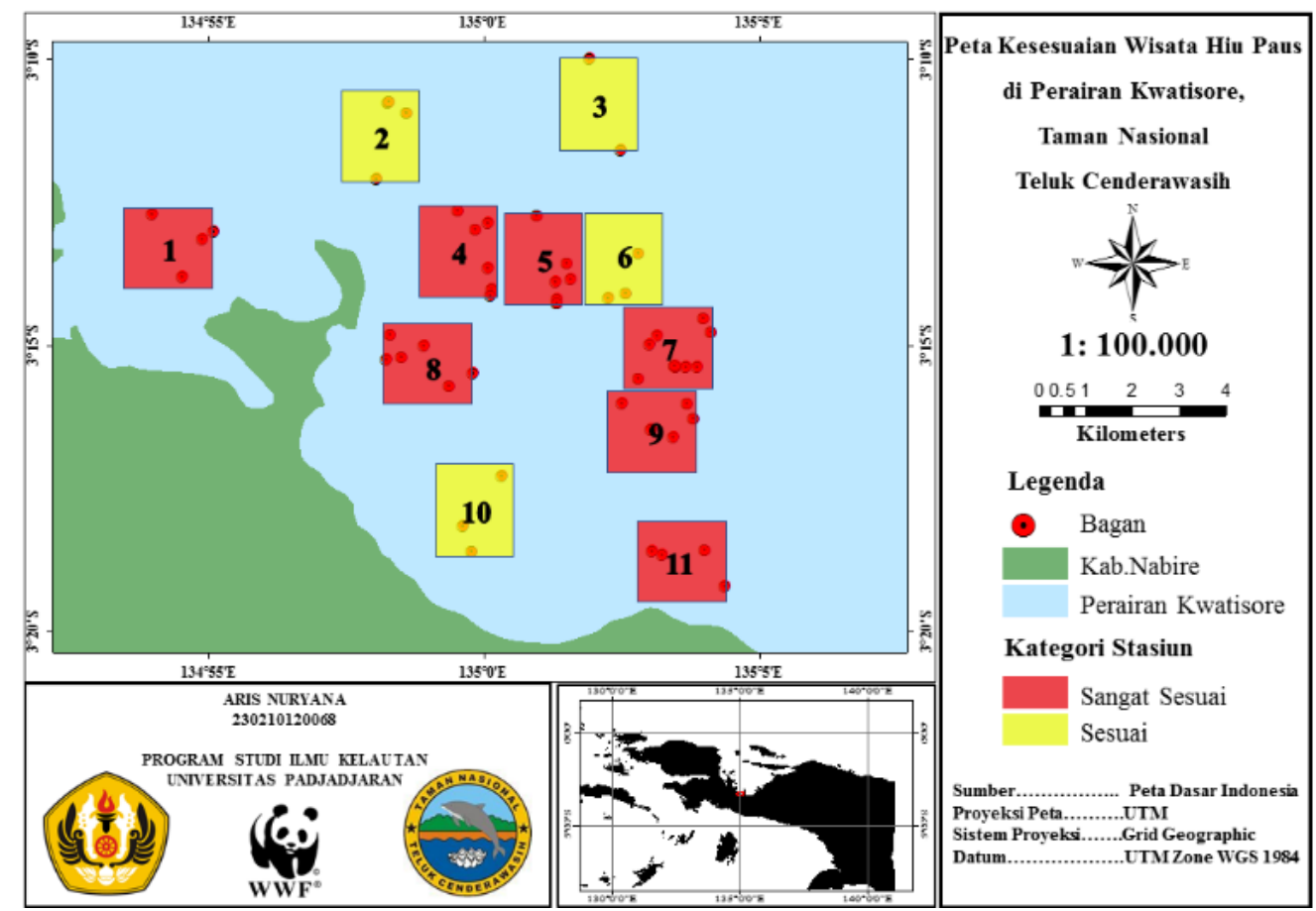

Gambar 3. Peta Kesesuaian Lahan Wisata Hiu Paus di Perairan Kwatisore

Picture 3. Land Suitability Map Tours Ehale Sharks in The Waters of Kwatisore

Pengukuran kecepatan arus untuk setiap stasiun memiliki variasi, yakni berkisar 0.14 $\mathrm{cms}^{-1}$ hingga $0.51 \mathrm{cms}^{-1}$.Stasiun yang memiliki kecepatan arus terendah adalah di stasiun 11 dan stasiun yang memiliki kecepatan arus terendah adalah stasiun 9.Berdasarkan letaknya, stasiun yang lebih dekat dengan daratan memiliki kecepatan arus yang lebih rendah dibandingkan stasiun yang lebih jauh.Ini dikarenakan oleh angin dan gelombang yang lebih besar pada stasiun-stasiun yang lebih jauh dengan daratan.Kecepatan arus sangat erat kaitannya dengan keamanan para wisatawan ketika berenang melihat hiu paus.Arus yang lemah sangat baik untuk kegiatan renang sedangkan arus yang kuat sangat berbahaya karena dapat menyeret orang-orang yang sedang melihat hiu paus.

Perhitungan kemunculan hiu paus di Perairan Kwatisore menggunakan data kemunculan hiu paus dari tahun 2013-2015 
menunjukkan bahwa kemunculan tertinggi terdapat pada stasiun 7 dengan jumlah kemunculan sekitar 245 ekor atau rata-rata bulanan sekitar 14 ekor/bulan. Angka ini cukuplah tinggi, karena dapat dikatakan pada area stasiun 7 hiu paus minimal dapat ditemukan selama 14 kali dalam 1 bulan. Selain itu, pada stasiun 7 yang terletak di arak Barat Kalilemon Resort dengan titik koordinat $135,043^{\circ} \mathrm{E}-135,068^{\circ} \mathrm{E}$ dan $3,241^{\circ} \mathrm{S}-3,261^{\circ} \mathrm{S}$ memiliki kecerahan perairan yang sangat tinggi yakni $16,1 \mathrm{~m}$ dan arus yang cukup tenang yakni $0,35 \mathrm{cms}^{-}$ ${ }^{1}$.Kondisi perairan seperti ini yang sangat mendukung untuk dilakukan aktivitas berenang bersama hiu paus.

\section{Daya Dukung Kawasan}

Daya dukung atau carrying capacity yang dimaksud dalam penelitian ini adalah kemampuan kawasan perairan untuk menerima sejumlah wisatawan dengan instensitas penggunaan maksimum terhadap sumberdaya alam atau objek wisata utama yakni hiu paus (Rhincodon typus) yang berlangsung secara terus menerus tanpa merusak lingkungan perairan dan mengganggu kelangsungan hidup hiu paus. Daya dukung alam perlu diketahui secara fisik, lingkungan dan sosial, hanya saja dalam penelitian ini, studi yang dikaji adalah daya dukung lingkungan yang berkaitan dengan jumlah wisatawan.Kebutuhan ruang menentukan seberapa besar ukuran fasilitas yang perlu dibangun untuk mengembangan wisata.

Penghitungan nilai daya dukung kawasan untuk melihat hiu paus didasarkan pada panduan atau himbauan dalam berinteraksi dengan hiu paus yang berlaku di Taman Nasional Teluk Cenderawasih yang menyebutkan bahwa dalam 1 kunjungan wisata dalam 1 bagan hanya diperbolehkan berisi 6 wisatawan dengan 1 pemandu. Setiap wisatawan harus menjaga jarak untuk memberikan ruang kepada hiu paus sekitar 2 $\mathrm{m}$ dari tubuh hiu paus dan 3 meter dari ekor hiu paus.

Terkait waktu wisatawan untuk melihat hiu paus juga dijelaskan dalam pedoman tersebut yang menyebutkan batas waktu maksimal untuk melihat waktu hiu paus adalah sekitar 60 menit atau 1
jam.Sedangkan terkait waktu yang disediakan oleh kawasan untuk melihat hiu paus dalam satu hari terkait dengan lama waktu kemunculan hiu paus.Menurut hasil wawancara dengan nelayan bagan menyebutkan bahwa hiu paus muncul ke permukaan dari waktu mereka menarik jaring ke atas hingga petang sore.Menurut Tania (2013) menyebutkan bahwa waktu terbaik untuk melihat hiu paus yakni dari pukul 06.00 WIT hingga 12.00 WIT. Oleh karena itu dalam 1 hari terdapat 6 jam waktu terbaik dalam melihat hiu paus.

Nilai daya dukung kawasan wisata untuk melihat hiu paus di perairan Kwatisore adalah sebesar 108 orang dengan banyak jumlah bagan yang digunakan sekitar 3 bagan.Nilai daya dukung kawasan tersebut menunjukan bahwa jumlah pengunjung maksimal yang diperbolehkan melakukan kegiatan wisata melihat hiu paus di wilayah perairan Kwatisore adalah 108 orang.Hal ini disebabkan karena adanya pembatasan jumlah pengunjung yang dimaksudkan untuk mengurangi dampak-dampak negatif yang dapat ditimbulkan dari adanya kegiatan wisata yang dilakukan pengunjung seperti tingkah nakal pengunjung untuk berinteraksi langsung (memegang, memberi makan langsung, menarik sirip) dengan hiu paus sehingga menggangu ruang gerak dari hiu paus tersebut.

Dibandingkan dengan nilai daya dukung kawasan wisata hiu paus di perairan Kwatisore, jumlah wisatawan yang berkunjung ke perairan Kwatisore masih sangatlah jauh. Wisatawan yang mengunjungi perairan Kwatisore tahun 2011 hanya berjumlah 747 dan pada tahun 2015 meningkat menjadi 5.722 wisatawan dalam 1 tahun yang terdiri dari 3.144 wisatawan lokal dan 2.564 wisatawan mancanegara. Nilai ini sangatlah jauh dengan nilai daya dukung kawasan yang mencapai 108 orang perharinya atau kurang lebih sekitar 38.448 orang dalam kurun waktu satu tahun. Untuk itu diperlukan adanya peningkatan promosi wilayah dan perbaikan atau bahkan penambahan sarana dan prasarana di kawasan wisata hiu paus di perairan Kwatisore yang nantinya akan menarik wisatawan untuk berkunjung ke kawasan wisata perairan Kwatisore ini. 
Donny Juliandri Prihadi : Daya Dukung Lingkungan dan Analisis Kesesuaian pada Wisata Hiu Paus

(Rhincodon typus) di Taman Nasional Teluk Cenderawasih, Kabupaten Nabire

\section{Simpulan}

Hasil penelitian menunjukkan secara umum kualitas lingkungan perairan Kwatisore sesuai untuk kegiatan wisata hiu paus.Berdasarkan baku mutu air laut, Perairan Kwatisore sesuai untuk wisata bahari dan habitat biota laut. Berdasarkan baku mutu air tawar, perairan kwatisore juga sesuai untuk air bersih dan air minum. Berdasarkan hasil analisis kesesuaian wisata, kawasan Perairan Kwatisoretergolong sangat sesuai (Stasiun 1, 4, 7, 8, 9 dan 11) dan sesuai ( 2, 3, 5, 6 dan 10) untuk kegiatan wisata hiu paus. Kemunculan setiap tahun dan kondisi lingkungan yang baik menjadi faktor utama dalam kegiatan wisata melihat hiu paus.Sedangkan berdasarkan nilai Daya Dukung Kawasan (DDK), jumlah wisatawan yang dapat berkunjung untuk melihat

\section{Saran}

Perlu penelitian lebih lanjut mengenai strategi pengelolaan terhadap pengembangan wisata hiu paus di Taman Nasional Teluk Cenderawasih agar pemanfaatan wisata disana dapat dioptimalkan dengan baik.Selain itu dampak negatif dari adanya kegiatan wisata juga dapat diminimalisir.Selain itu, perlu dilaksanakannya monitoring rutin tentang kemunculan hiu paus seperti yang dilakukan pada tahun 2013-2015 sehingga data mengenai kemunculan hiu paus dan lebih lengkap.

\section{Daftar Pustaka}

Adi, A. B., Mustafa, A., Ketjulan, R. 2013. Kajian Potensi Kawasan dan Kesesuaian Ekosistem Terumbu Karang di Pulau Lara Untuk Pengembangan Ekowisata Bahari. Universitas Halueleo.

Atmodjo, E., J. Wanggai, M. Yuwono., Pattiselano, F. 1998. Studi Pengelolaan Kawasan Lindung di Kabupaten Dati, II Nabire. Laporan Survey Pemantapan Data Dasar Pusat Studi Lingkungan Universitas Cenderawasih Manokwari.

Azis, H. 2013. Analisis Kualitas untuk Pemanfaatan Pantai Boe Sebagai
Tempat Wisata Permandian Pada

Musim Barat di Desa

Mappakalompo Kecamatan

Galesong Kabupaten

Takalar. Universitas Hasanuddin.

Azourmanian, Z., J. Holmberg, and B. Norman. 2005. An Astronomical Pattern- Matching Algorithm for Computer Aided Identification of Whale Sharks Rhincodon typus. Journal of Aplied Ecology 42: 110

BKSDA VIII. Maluku Irja. 1995. Himawan. 2015. Size and maturity status of the whale shark (Rhincodon typus) at Ningaloo Reef in Western Australia. Fisheries Research 84: 81-86.

Balai Besar TNTC. 2013. Statistik Balai Besar Taman Nasional Teluk Cenderawasih.Manokwari.108 hal.

Bawole, R. et al. 2011. Keberlanjutan Penatakelolaan Zona Pemanfaatan Tradisional dalam Kawasan Konservasi Laut Taman Nasional Teluk Cenderawasih Papua Barat. Institut Pertanian Bogor.

Brunnschweiler, J.M., H. Baensch, S.J. Pierce, dan D.W. Sims. 2009. DeepDiving Behaviour of A Whale Shark Rhincodon typus during LongDistance Movement in the Western Indian Ocean. Journal of Fish Biology 74: 706-714.

Craven, S. 2012. Whale Shark of Oslob.A Report on The Status of The Whale Shark Watching Tourist Industry in Tan-awan, Oslob, Cebu.48 hal.

Direktur Konservasi Kawasan dan Jenis Ikan. 2015. Pedoman Umum Monitoring Hiu Paus di Indonesia. Kementerian Kelautan dan Perikanan.

Himawan. 2015. Size and maturity status of the whale shark (Rhincodon typus) at Ningaloo Reef in Western Australia. Fisheries Research 84: 81-86.

Hutabarat,A. A., Yulianda F., Fahrudin, A.,Harteti S., Kusharjani. 2009. Pengelolaan Pesisir dan Laut Secara Terpadu. Bogor: Pusdiklat Kehutanan-Departemen Kehutanan RI-SECEM-Korea International Cooperation Agency.

Inskeep, E. 1991.Tourism Planning: an Integrated and Sustainable 
Development Approach. New York: Van Nostrand Reinhold.

Kanwil Kehutanan Irja \& BKSDA VIII Maluku Irian Jaya. 1995. Leaflet Taman Nasional Laut Teluk Cenderawasih.

Kanwil Kehutanan Irja. 1995. Pengembangan Pengelolaan Taman Nasional Laut Teluk Cenderawasih.Makalah Rapat Koordinasi Pembangunan Taman Nasional Laut Teluk Cenderawasih.

Keputusan Menteri Kelautan dan Perikanan Republik Indonesia No. 18 Tahun 2013 tentang Penetapan Status Perlindungan Penuh Ikan Hiu Paus (Rhincodon Typus) dan Bentuk Eksploitasi di dalamnya.

Keputusan Menteri Lingkungan Hidup No. 51 Tahun 2004 Tentang Baku Mutu Air Laut Untuk Wisata Bahari

Norman, B. 2002.CITES Identification Manual WHALE SHARK (Rhincodon typus Smith 1829). Australia.

Norman, B. 2005.Rhincodon typus.The IUCN Red List of Threatened Species.Version 2014.<www.iucnredlist.org $>$.

Nybakken, J.W. 1992. Biologi Laut : Suatu Pendekatan Ekologis. Gramedia Jakarta.

Odum, E. P. 1971. Fundamental Of Ecology Third Editio. W. B. Sounder Company, Toronto.

Pattiselano, F. 2004. Dukungan Potensi Biologi Terhadap Ekoturisme Di Taman Nasional Laut Teluk Cenderawasih. Universitas Negeri Papua.

Pattiselano, F., Wanna, J. F. 2014. Peduli Pulau-Pulau Kecil : Lindungi Habitat Kuskus (Phalangeridae) di Teluk Cenderawasih. Wetlands International.

Peraturan Menteri Negara Lingkungan Hidup Nomor 17 Tahun 2009 Tentang Pedoman Penentuan Daya Dukung Lingkungan Hidup Dalam Penataan Ruang Wilayah

Peraturan Menteri Kehutanan (Permenhut) Nomor P.19/ Menhut-II/2004 tentang kolaborasi dalam pengelolaan kawasan suaka alam dan kawasan pelestarian alam

Peraturan Menteri Kesehatan No. 416 Tahun 1990 Tentang : Syarat-syarat Dan Pengawasan Kualitas Air.

Peraturan Menteri Kesehatan No. 492 Tahun 2010 Tentang : Persyaratan Kualitas Air Minum..

Suruan, S.S., Kamal, M.M., Kurnia, R. dan Bawole, R. Pengaruh Bagan Terhadap Keberadaan Hiu Paus (Rhincodon typus) Di Perairan Kwatisore, Taman Nasional Teluk Cenderawasih (TNTC) Provinsi Papua. Journal of Marine and Coastal Science, Vol. 6 No.2, Juni 2017.

Tambunan, J.M., Anggoro, S. dan Purnaweni, H. 2013. Kajian Kualitas Lingkungan dan Kesesuaian Wisata. Prosiding Seminar Nasional Pengelolaan Sumberdaya Alam danLingkungan 2013: 356-362.

Tania, C., K. Sumolang, dan A. Wijonarno. 2013. Pengamatan Insidental di Taman Nasional Teluk Cenderawasih. Laporan Pengamatan Wasior.

Tania, C. 2014. Pemantauan Hiu Paus Di Taman Nasional Teluk Cenderawasih.WWF-Indonesia.

Undang-undang Nomor 32 Tahun 2009 tentang Perlindungan dan Pengelolaan Lingkungan Hidup

Watopa, B. F. 1995. Pengelolaan Taman Nasional Laut Teluk Cenderawasih.Makalah Seminar Mahasiswa Kehutanan Indonesia.

WCS Indonesia. 2010. A Review of Whale Shark Occurrences in Indonesia: An initial effort on mapping its spatial and seasonal pattern. Bogor.

Winara, A., Muchtar, A. S. 2011. Potensi Kolaborasi Dalam Pengelolaan Taman Nasional Teluk Cenderawasih Di Papua. Balai Penelitian Teknologi Agroforestry.

Yulianda, F. 2007. Ekowisata Bahari sebagai Alternatif Pemanfaatan Sumberdaya Pesisir Berbasis Konservasi.Disampaikan pada Seminar Sains 21 Februari 2007 pada Departemen Manajemen Sumberdaya Perairan, FPIK.IPB. 